\title{
DFT Cancer Energy Barrier and Spectral Studies of Aspirin, Paracetamol and Some Analogues
}

\author{
Anwar El-Shahawy \\ Chemistry Department, Faculty of Science, Assiut University, Assiut, Egypt. \\ Email: anwarshahawy@yahoo.com \\ Received October $23^{\text {rd }}$, 2013; revised November $25^{\text {th }}$, 2013; accepted December $5^{\text {th }}$, 2013 \\ Copyright (C) 2014 Anwar El-Shahawy. This is an open access article distributed under the Creative Commons Attribution License, \\ which permits unrestricted use, distribution, and reproduction in any medium, provided the original work is properly cited. In accor- \\ dance of the Creative Commons Attribution License all Copyrights (C) 2014 are reserved for SCIRP and the owner of the intellectual \\ property Anwar El-Shahawy. All Copyright (C 2014 are guarded by law and by SCIRP as a guardian.
}

\section{ABSTRACT}

Comparative DFT computations were studied between Paracetamol (PA) and its analogues such as p-nitroacetanilide (PA-NO ${ }_{2}$ ), p-bromoacetanilide (PA-Br) and $\mathrm{N}$-acetylanthranilic acid (NAA) which can be considered also as analogue of Aspirin (ASP). As well, Thio-Aspirin, Acetyl-Thio-Salicylic acid, (TASP) is another analogue of ASP. From DFT studies, it has been concluded that PA and its analogues have the predominant trans-conformers with respect to directions of the carbonyl group in the acetyl moiety and the amino-hydrogen atom but the predominant conformer of NAA molecule is the cis-form. Phenacetin (PH) molecule which has ethoxy group in the Para-position instead of the hydroxyl group in the Para-position in PA molecule is another analogue of PA. The electron transfer energy between the drugs and the nucleic acid bases can be illustrated as cancer energy barrier. The cancer energy barriers were calculated from the DFT parameters for all the studied molecules showing the carcinogenic effect. The metabolized product $\mathrm{N}$-acetylimidoquinone, $\mathrm{m}$-PA, is produced in the liver from PA and PH. m-PA has higher electron affinity more than those of the nucleic acid bases indicating to the strong electronic withdrawing power from the nucleus in the human being liver cell, hence m-PA is responsible for the carcinogenic behavior of the liver cell since it has low energy barrier with guanine, $0.3 \mathrm{eV}$. Therefore the electron transfer between $\mathrm{m}$-PA and guanine takes place spontaneously in the liver. From CI calculations it has been concluded that the singlet transition energies for the trans and cis conformers of PA are the same. The comparative spectral studies have been scanned for some analogues in the visible and UV regions using solvents of different polarities. The complex between PA and $\mathrm{Zn}^{2+}$ was studied by DFT method.

\section{KEYWORDS}

\section{B3LYP; CI; Paracetamol; Aspirin; Electron Transfer; Conformers; UV Spectra}

\section{Introduction}

Paracetamol (acetaminophen) is worldwide used as analgesic and antipyretic drug [1] and there is a review by Vial et al. [2] including 93 references discussing the clinical side effects of paracetamol in terms of the following system processes: allergic and skin; hematol; renal diseases; lactation of pregnant; carcinogenesis. Bioavailability effect of ethyl alcohol on paracetamol was studied by Wojcicki et al. [3] in healthy men. Goto et al. studied the charge transfer ability values for various pyridines and pyrimidines by CNDO/2 [4].

Charge transfer complex formation between nucleic acid bases and isoproterenol was confirmed using UV absorption measurement by Taha et al. [5]. Tautomeric structures of uracil and its effect on the electrochemical corrosion behavior of mild steel in acidic medium were studied using CNDO calculations by Makhlouf et al. [6]. The hydrogen bonding in drug-receptor interactions has been studied by Ghafourian et al. [7]. Sever hepatotoxicity and nephrotoxicity due to the accumulation of toxic metabolites of paracetamol were studied by Moffat [8]. The charge transfer complex formation between adenine, cytosine, thymine and uracil with catechol in acidic medium was studied by Al-Obeidi et al. [9]. Lahiri [10] studied the charge transfer complex formation between 
oxytetracycline and tetracycline with purines, pyrimidines and amino acids. The charge transfer complex formation between 4,4'-dimethoxydiquinone with uracil has been studied via CNDO calculations by El-Shahawy et al. [11]. Paracetamol toxicity is manifested primarily in the liver. Treatment with $\mathrm{N}$-acetyl-cysteine (NAC), if started within $10 \mathrm{~h}$ from ingestion, can prevent hepatic damage in most cases [12].

The therapy of rheumatism started since thousands of years ago with the use of decoctions or extracts of herbs or plants such as willow bark or leaves, most of which turned out to contain salicylates. Following the advent of synthetic salicylate, Felix Hoffman, working at the Bayer Company in Germany, made the acetylated form of salicylic acid in 1897. This drug was named "Aspirin" and became the most widely used medicine of all time. In 1971, Vane discovered the mechanism by which Aspirin exerts its anti-inflammatory, analgesic and antipyretic actions. He proved that Aspirin and other non-steroid anti-inflammatory drugs (NSAIDs) inhibit the activity of the enzyme now called cyclooxygenase (COX) which leads to the formation of prostaglandins (PGs) that cause inflammation, swelling, pain and fever. However, by inhibiting this key enzyme in PG synthesis, the Aspirin-like drugs also prevented the production of physiologically important PGs which protect the stomach mucosa from damage by $\mathrm{HCl}$. This conclusion provided a unifying explanation for the therapeutic actions and shared side effects of the aspirin-like drugs. Twenty years later, with the discovery of a second COX gene, it became clear that there are two iso-forms of the COX enzyme. The constitutive iso-form, COX-1, supports the beneficial homeostatic functions, whereas the inducible iso-form, COX-2, becomes unregulated by inflammatory mediators and its products cause many of the symptoms of inflammatory diseases such as rheumatoid and osteoarthritis [13].

\section{Experimental Work}

\subsection{Materials}

Paracetamol (Chem. Pharm. Works, Dupnitsa) was recrystallized from water to show a melting point of $168^{\circ}$. $\mathrm{N}$-acetylanthranilic acid (NAA) CAS NO. (89-52-1) (2acetamidobenzoic acid) $\left(\mathrm{C}_{9} \mathrm{H}_{9} \mathrm{NO}_{3}\right)$ of M.F 179.1, shows a melting point of $184^{\circ} \mathrm{C}-187^{\circ} \mathrm{C}$; acetylthiosalicylic acid (TASP) CAS. No. (55819-78-8) has melting point at $260^{\circ} \mathrm{C}-262^{\circ} \mathrm{C}$, Aspirin (ASP) CAS No. (50-78-2) (acetylsalicylic acid or 2-acetoxybenzoic acid) has melting point at $140^{\circ} \mathrm{C}-142^{\circ} \mathrm{C}$.

All organic solvents used, such as ethanol, methanol, isopropanol, chloroform, carbon tetrachloride, and diethylether were extra pure Prolabo and Merk grades.

\subsection{Instrumentation}

The UV-visible spectra of some of the studied compounds had been scanned by UV-2101 PC UV-vis scanning spectrophotometer Shimadzu.

The temperature effect on the PA spectrum has been scanned by Perkin Elmer Lambda 35 UV/V is spectrophotometer USA.

\section{Method of Calculations}

\subsection{Computational Studies}

Computational studies on the isolated molecules in the gas phase were performed by the aid of GAUSSIAN 03 package. Minimum energy structures have been achieved using B3LYP/6-31** G basis set. Calculations were performed on the minimum energy structures using the closed shell Hartree-Fock, Becke's three parameters density functional theory, DFT, [14] in combination with the Lee, Yang and Parr correlation functional B3LYP [15] with basis set $6-31^{* *} \mathrm{G}$. The differentiation between the conformers' cis and trans was based on the total energy difference which have been calculated via SCF using RHF for these types of molecules and UHF for the molecular ions (cations and anions).

With respect to DFT calculations, it has been carried out as B3LYP/6-31** G and the energy of the density function theory can be represented as follows $[16,17]$ :

$$
\begin{aligned}
E|\rho|= & \frac{-\hbar^{2}}{2 m_{e}} \sum_{i=1}^{n} \int \psi_{i}^{*}(r)_{1} \nabla^{2} \psi_{i}\left(r_{1}\right) d r_{1} \\
& -\sum_{i=1}^{n} \int \frac{z_{r} e^{2}}{4 \pi \varepsilon_{0} r_{11}} \rho\left(r_{1}\right) d r_{1} \\
& +\frac{1}{2} \int \frac{\rho\left(r_{1}\right) \rho\left(r_{2}\right) e^{2}}{4 \pi \varepsilon_{0} r_{12}} d r_{1} d r_{2}+E_{x c}|\rho|
\end{aligned}
$$

where $\rho$ is the electron density.

$$
\rho=\sum_{i=1}^{n}\left|\psi_{i(r)}\right|^{2}=\sum_{i}^{n} C_{i(r)}^{2}
$$

where $C_{i}$ is the eigenvectors and

$$
\hat{H}_{i}=\frac{-\hbar^{2}}{2 m_{e}} \nabla_{i}^{2}-\sum_{i}^{n} \frac{z_{1} e^{2}}{4 \pi \varepsilon_{0} r_{12}}+\int \frac{\rho\left(r_{2}\right) e^{2}}{4 \pi \varepsilon_{0} r_{12}}+V_{x c}\left(r_{1}\right)
$$

where $\hat{H}_{i}$ is the Hamiltonian of the energy.

\subsection{Electron Transfer Studies}

The electron transfer energy in the CT-complex between the donor and the acceptor (cation and anion) was calculated according to the following equation [18].

$$
E_{C T}=I_{D}-E_{A}-\left(C^{+}+C^{-}\right)
$$

where $I_{D}$ is the ionization potential of the donor and $E_{A}$ is 
the electron affinity of the acceptor. $C^{+}$is the columbic potential energy of the donor as a cation, and $C^{-}$is the columbic potential energy of the acceptor as an anion. The columbic potential energy can be calculated, according to the following equation [18].

$$
C=14.398 \sum_{i}^{N} \sum_{j \neq i}^{N} \frac{Z_{i} Z_{j}}{r_{i j}} \mathrm{eV}
$$

where $Z_{i}$ and $Z_{j}$ are the charge densities and $r_{i j}$ is the distance between two atoms in the molecule of $N$ atoms. The ET-band position in $\mathrm{nm}$ can be obtained by dividing 1240.824 by the electron transfer energy in electron volts.

\subsection{Spectroscopic Parameters}

The Einstein transition probability coefficients of emission, $A_{i f}$, and absorption, $B_{i f}$, between two initial (i) and final $(f)$ electronic states are given as follows [19]:

$$
\begin{gathered}
A_{i f}=\frac{64 \pi \mathrm{e}^{\sim} v^{3} 2}{3 h} G_{f} D_{i f} \\
B_{i f}=\frac{8 \pi \mathrm{e}^{2}}{3 h^{2} C} G_{f} D_{i f}
\end{gathered}
$$

where $h$ is the Planck's constant, e is the electron charge, $c$ the light velocity, $3 \times 10^{10} \mathrm{~cm} \mathrm{~s}^{-1}$, $v$ the wave number of radiation in $\mathrm{cm}^{-1}, G_{f}$ the degeneracy of the final state, $D_{\text {if }}$ is the dipole strength and $\tau$ is the life time of the excited state.

Substituting the numerical values and assuming the singlet degeneracy for the excited state, then:

$$
\begin{aligned}
& A_{i f}=7.24 \times 10^{10} v D_{i f} \\
& B_{i f}=14.50 \times 10^{24} D_{\text {if }}
\end{aligned}
$$

The oscillator strength, $f_{i j}$, is the measure of the intensity.

$$
f=\frac{8 \pi^{2} m_{\mathrm{e}} C}{3 h} G_{f} \tilde{v} D_{i f}=1.085 \times 10^{11} G_{f} \tilde{v} D_{i f}
$$

Also the oscillator strength can be related to the absolute intensity as follows:

$$
f=0.102\left(\frac{m C^{2}}{N \pi \mathrm{e}^{2}}\right) \int \varepsilon \mathrm{d} \tilde{v}=4.315 \times 10^{-9} \int \varepsilon \mathrm{d} \tilde{v}
$$

where $m$ is the electron mass, $N$ the Avogadro's number, and $\varepsilon$ is the molar extinction coefficient. If a molecule is in an excited state then, in the absence of an external electromagnetic field, on the average, after a time $\tau$ it will emit a photon.

$$
\tau=\frac{1}{A_{i f}}
$$

Generally $D_{i f}$ can be calculated numerically as follows:

$$
\mathrm{D}_{\text {if }}=4.23671 \times 10^{-20} \times \frac{c \hbar}{v} \varepsilon_{\text {max. }} .
$$

where $\hbar$ is the half width of the absorption band in $\mathrm{cm}^{-1}$. Hence, the oscillator strength can be calculated directly as follows:

$$
f_{\mathrm{ij}}=4.6 \times 10^{-9} \varepsilon_{\max } \times \hbar
$$

\subsection{Configuration Interaction Studies}

The configuration interaction [19] between the ground configuration Eigenfunction $\Phi_{0}$ with the excited singlet configuration Eigenfunctions containing the transitions between the upper seven HOMO's, $\psi_{i}$ and the lowest seven LUMO's, $\psi_{i}$ for each molecule under study via ZINDO program to give the transition energies between the ground state, $\Psi_{0}=\Phi_{0}$, and other three singlet excited states, $\Psi_{e \times 1}, \Psi_{e \times 2}$ and $\Psi_{e \times 3}$ which are the linear combination of the configuration Eigenfunctions, $\psi_{i} \psi_{j}$ containing the transitions between the upper seven HOMO's and the lowest seven LUMO's.

\section{Result and Discussion}

\subsection{Conformational Studies}

PA is metabolized primarily in the liver [20-21], into toxic and non-toxic products. Three metabolic pathways are notable, Figure 1. The hepatic enzyme system metabolizes Paracetamol, forming the toxic product as NAPQI ( $N$-Acetyl-P-benzo-Quinone Imine) or $\mathrm{N}$-acetylimido-quinone which has symbol (m-PA) Figure 2 for simplicity. All three pathways yield final products that are inactive, non-toxic, and eventually excreted by the kidneys. The intermediate product m-PA is also produced via the metabolism of PH, Figure 2, in the liver, Figure 1. This means that m-PA is primarily responsible for the toxic effects of PA and PH.

Then it is interesting to use quantum mechanical DFT theory to study the situation of the toxicity of this product, m-PA, with respect to other derivatives of acetanilide such as para-nitroacetanilide $\left(\mathrm{PA}-\mathrm{NO}_{2}\right)$ and parabromoacetanilide (PA-Br) which have good structural resemblance with $\mathrm{PA}$ and $\mathrm{PH}$. Also it is necessary to compare the study of PA with its analogues from the conformers' point of view. The cis-conformer is the structure in which the amino hydrogen atom and the carbonyl group are in the same side. The trans-conformer is the structure in which the amino hydrogen atom and the carbonyl group are in opposite sides, Figure 3. Nacetylanthranilic acid (NAA) molecule has structural resemblance with PA and ASP, Figure 4.

The existence of conformers cis and trans, Figure 3, is probable due to the small energy difference between them in the following molecules: $\mathrm{PA}, \mathrm{PH}, \mathrm{PA}-\mathrm{NO}$, 


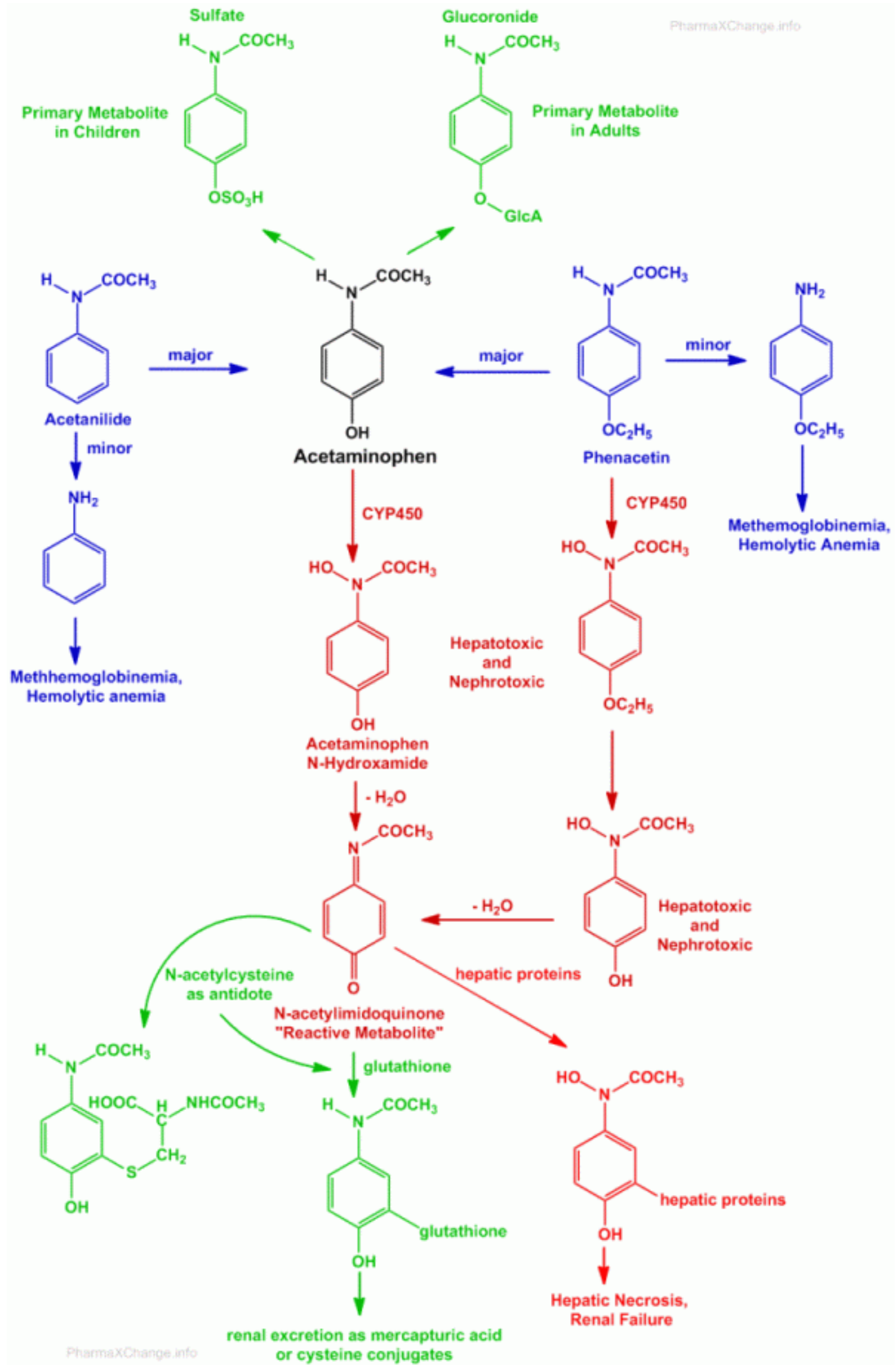

Figure 1. Scheme of metabolism of PA and PH to form m-PA. 
<smiles>[CH]N(C(C)=O)c1ccc(O)c(SC2=CC(=O)C=CC2=NC(C)=O)c1</smiles>

Figure 2. Metabolized product, m-PA from PA, and PH.<smiles>[X]c1ccc(NC(C)=O)cc1</smiles>

Cis-Form<smiles>[X]c1ccc(N([2H])C(=C)C)cc1</smiles>

Trans-Form

Figure 3. The Conformers of $\mathrm{X}=\mathrm{OH}, \mathrm{OEt}, \mathrm{NO}_{2}$ and $\mathrm{Br}$.

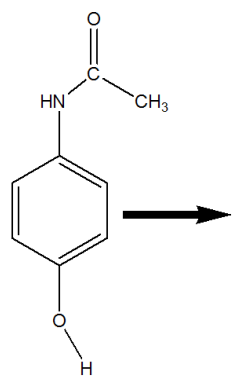

PA

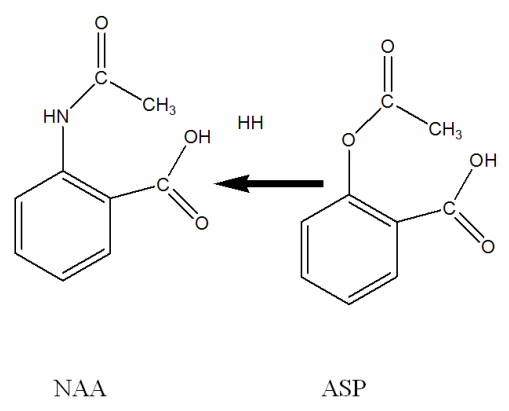

Figure 4. Structural resemblance between NAA with PA and ASP.

$\mathrm{PA}-\mathrm{Br}$ and NAA. The ratio of the existence of the two conformers depends on the energy difference between them and the temperature, $27^{\circ} \mathrm{C}$, according to Boltzmann equation [19].

From the previous Table 1, it is clear that the transconformer has the lower energy in PA and PA analogues in contrary to NAA molecules which have the predominant cis-conformer of lower energy. The energy difference between the two conformers is a fraction of electron volt therefore their abundance is probable. The transconformer of NAA molecules is in small fraction due
Table 1. B3LYP/6-31 ${ }^{* *} \mathrm{G}$ Energy difference between the conformers at $27^{\circ}$.

\begin{tabular}{cccc}
\hline Compound & $\Delta E \mathrm{eV}$ & $N / N_{0}$ & $N$ \\
\hline $\mathrm{PA}$ cis/trans & 0.16055 & $2.00404 \times 10^{-3}$ & $1.207037 \times 10^{21}$ \\
$\mathrm{PH}$ cis/trans & 0.27211 & $2.67 \times 10^{-5}$ & $106135 \times 10^{19}$ \\
$\mathrm{PA}^{-N_{2}}$ cis/tr & 0.34531 & $1.5738 \times 10^{-6}$ & $9.4792 \times 10^{17}$ \\
$\mathrm{PA}-\mathrm{Br}$ cis/trans & 0.18232 & $8.6309 \times 10^{-4}$ & $5.19839 \times 10^{20}$ \\
$\mathrm{NAA}$ trans/cis & 0.76355 & $1.47335 \times 10^{-13}$ & $2.3603 \times 10^{10}$ \\
\hline
\end{tabular}

$\Delta E$ is the energy difference between the two conformers. $N / N_{\mathrm{o}}$ is the ratio between the two conformers. $\mathrm{N}$ is the number of the conformer molecules of the higher energy in one mole.

to the relative large energy difference with respect to the lower energy cis-form which is the predominant conformer in the NAA molecule at $27^{\circ} \mathrm{C}$, Table 1.

\subsection{Electron Transfer Studies}

These studies concerned with the electron transfer energy of these molecules with nucleic acid bases, Figure 5 to conclude the carcinogenic character of the studied molecules via the electron transfer values. The electron transfer energy depends mainly on the ionization potential of the donor, the electron affinity of the acceptor and the potential energies of the donor (cation) and the acceptor (anion). The ionization potential and the electron affinity were calculated via DFT method using the option B3LYP/6-31 ${ }^{* *} \mathrm{G}$ for the minimum energy structures of these compounds. Also the charge transfer energy depends not only on the ionization potential and electron affinity but also on the columbic potential energies of the cation (donor) and the anion (acceptor) using the Cartesian coordinates of the standard orientation and the Mulliken charge densities of the molecular ions using the data coming from the DFT method using Gaussian 03 program.

The acceptor and the donor can be defined by the relative values of the ionization potential energy and electron affinity of the two interacted molecules. The molecule having higher electron affinity and high ionization potential acts as acceptor to form an anion in the et-complex. The molecule having lower electron affinity and lower ionization potential acts as donor to form a cation in the et-complex.

Since the electron affinities of PA, PH, Figure 2, and $\mathrm{PA}-\mathrm{Br}$ are lower than those of nucleic acid bases therefore they act as donor to produce charge transfer complex in which these molecules are cations and the nucleic acid bases are anions. But m-PA, Figure 2, $\mathrm{PA}-\mathrm{NO}_{2}, \mathrm{NAA}$, Figure 6, ASP and TASP, Figure 7, have electron affinities larger than those of the nucleic acid bases, therefore they act as acceptor to be in the anionic-form in the et-complex with the cationic nucleic acid bases in the human being nucleus to render the cell behaves abnormally i.e. carcinogenic. 
From the electron transfer energies Tables 2-5 it can be concluded that the m-PA of quinoide structure has the lowest energy transfer, $0.382 \mathrm{eV}$, with guanine indicating to the easiest transfer of an electron to m-PA to render the nucleus is carcinogenic i.e. ionic., Table 6.

The electron transfer energy can be illustrated as cancer energy barrier whenever it has large value this means the safety of the drug from the carcinogenic effect. For example PA-Br, Table 6, has electron transfer energies with the nucleic acid bases among 4.0 and $5.012 \mathrm{eV}$. This means the strong safety of this drug from the carcinogenic effect. On the other hand, from the previous Table 6, it has been shown that the cancer energy barrier of M-PA with guanine is very small i.e. $0.382 \mathrm{eV}$ therefore the contact of M-PA with the nucleus in the human being cell in the liver produces spontaneous electron transfer from Guanine to M-PA to produce ionic nucleus; hence the cell behaves abnormally which is known as cancer. Therefore, PA drug itself is safe only in the case of presence of glutathione preventing the formation of the quinoide structure as in M-PA, Figure 1. Glutathione, a tripeptide, $\gamma$-L-glutamyl-L-cysteinylglycine, was isolated from yeast, muscles, and liver tissue and is widely distributed in nature. So long as Phenacetin ( $\mathrm{PH}$ ) produces the quinoide structure, M-PA, as the same situation of PA in

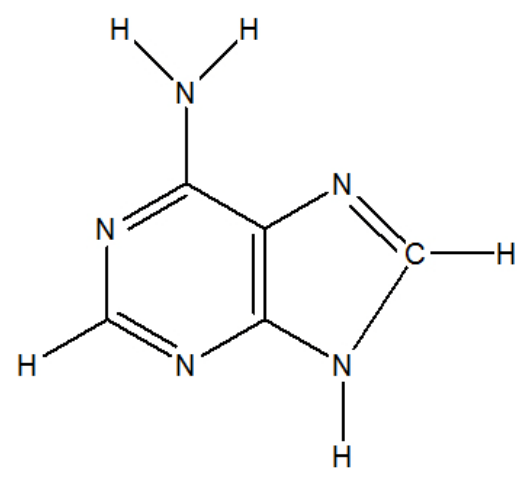

Adenine<smiles></smiles>

Uracil, $\mathbf{U}$ the liver, hence it is harmful as PA drug. Finally, it can be concluded that the probability of the carcinogenic effect is proportional inversely with the value of the electron transfer energy.

From other point of view, regarding n-acetylanthranilic acid (NAA), Figure 6, it has structural resemblance with Aspirin and Paracetamol, Figure 4, and it has considerable cancer energy barrier between 2.071 and 4.544 $\mathrm{eV}$ which is not far from the cancer energy barrier of ASP. This means that NAA, Figure 6, as a drug is safer from the carcinogenic effect and it can be advisable to use this compound as an alternative drug instead of ASP, Figure 7, and PA, Figure 2.

In June 2009, an FDA [22] advisory committee recommended that new restrictions should be placed on Paracetamol usage in the United States to protect people from the potential toxic effects. The maximum dosageto be consumed at any given time would be decreased from $1000 \mathrm{mg}$ to $650 \mathrm{mg}$, while combinations of Paracetamol and narcotic analgesics would be prohibited. Committee members were particularly concerned by the fact that the present maximum dosages of Paracetamol had been shown to produce alterations in hepatic function. The FDA has not implemented their recommendations as of October 2010.<smiles>c1nc2nc3c4[nH]c(n1)c2=c-3-n-4</smiles>

Guanine<smiles></smiles>

Cytosine, $\mathrm{C}$

Figure 5. Nucleic acid bases (N.A.B.). 
Table 2. Electron transfer energies of the studied compounds with adenine.

\begin{tabular}{ccccc}
\hline Compound & $\begin{array}{c}I_{p} \mathrm{eV} \text { of } \\
\text { donor }\end{array}$ & $\begin{array}{c}E_{a} \mathrm{eV} \text { of } \\
\text { acceptor }\end{array}$ & $\begin{array}{c}C \mathrm{eV} \\
C=C+C^{+}\end{array}$ & $E_{e t} \mathrm{eV}$ \\
\hline PA cis & 6.1634 & 1.2672 & 0.285692 & 4.61051 \\
PA trans & 5.8374 & 1.2672 & 0.149310 & 4.42089 \\
PH cis & 5.8105 & 1.2672 & 1.755315 & 3.48399 \\
PH trans & 5.7106 & 1.2672 & 0.088662 & 4.35474 \\
M-PA & 6.4061 & 4.2400 & 0.325528 & 1.8406 \\
PA-No 2 cis & 6.4061 & 2.9200 & 0.472047 & 3.0141 \\
PA-NO ${ }_{2}$ trans & 6.4061 & 2.7630 & 0.330156 & 3.3129 \\
PA-Br cis & 6.5052 & 1.2672 & 0.225956 & 5.012044 \\
PA-Br trans & 6.2668 & 1.2672 & 0.404115 & 4.59549 \\
NAA cis & 6.4061 & 2.1146 & 0.491959 & 3.79954 \\
NAA trans & 6.4061 & 2.2656 & 0.664803 & 3.475697 \\
ASP & 6.4061 & 1.9173 & 0.491308 & 3.997492 \\
TASP & 6.4061 & 2.3979 & 0.460636 & 3.547564 \\
\hline
\end{tabular}

N.B. $I_{p}$ for adenine is equal to $6.4061 \mathrm{eV}$ when it is donor. $E_{a}$ for adenine is equal to $1.2672 \mathrm{eV}$ when it is acceptor. $C$ is the columbic energy of the anion and cation. $E_{e t}$ is the electron transfer energy.

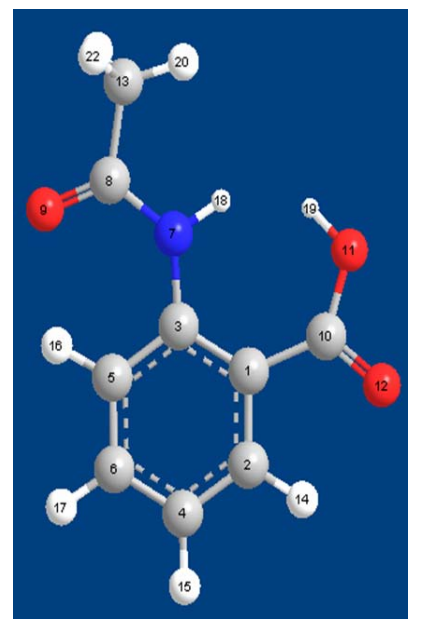

Figure 6. Minimum energy structure of trans-NAA.

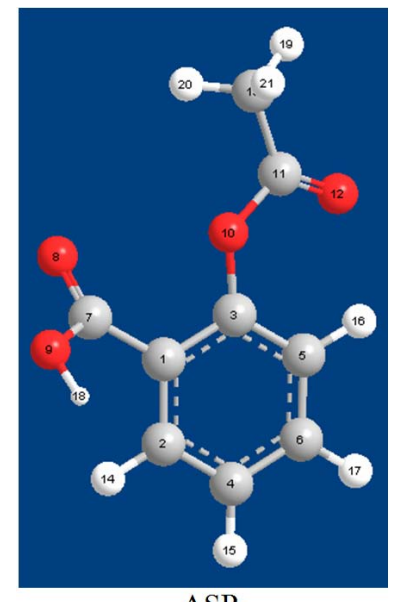

ASP

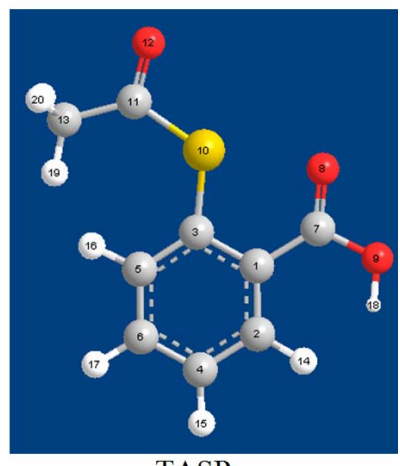

TASP

Figure 7. Minimum energy structures of ASP and TASP.
Table 3. The Electron transfer energies of the studied compounds with guanine.

\begin{tabular}{ccccc}
\hline Compound & $\begin{array}{c}I_{p} \mathrm{eV} \text { of } \\
\text { donor }\end{array}$ & $\begin{array}{c}E_{a} \mathrm{eV} \text { of } \\
\text { acceptor }\end{array}$ & $\begin{array}{c}C \mathrm{eV} \\
C=C^{-}+C^{+}\end{array}$ & $E_{e t} \mathrm{eV}$ \\
\hline PA cis & 6.1634 & 1.2828 & 0.86550 & 0.40151 \\
PA trans & 5.8374 & 1.2828 & 0.72931 & 3.82529 \\
PH cis & 5.8105 & 1.2828 & 0.75534 & 3.77236 \\
PH trans & 5.7106 & 1.2828 & 0.75555 & 3.67225 \\
M-PA & 6.1879 & 4.2400 & 1.56174 & 0.3816 \\
PA-No 2 cis & 6.1879 & 2.9200 & 1.71268 & 1.55522 \\
PA-NO ${ }_{2}$ trans & 6.1879 & 2.7630 & 1.57079 & 1.85411 \\
PA-Br cis & 6.5052 & 1.2828 & 0.80576 & 4.41664 \\
PA-Br trans & 6.2668 & 1.2828 & 0.98392 & 4.00008 \\
NAA cis & 6.1879 & 2.1146 & 1.73259 & 2.34071 \\
NAA trans & 6.1879 & 2.2656 & 1.90543 & 2.01687 \\
ASP & 6.1879 & 1.9173 & 1.73194 & 2.53866 \\
TASP & 6.1879 & 2.3979 & 1.70127 & 2.08873 \\
\hline
\end{tabular}

N.B. Ionization potential of guanine is $6.1879 \mathrm{eV}$ when it acts as donor. Electron affinity of guanine is $1.2828 \mathrm{eV}$ when it acts as acceptor.

Table 4. Electron transfer energies of the studied compounds with Cytosine.

\begin{tabular}{ccccc}
\hline Compound & $\begin{array}{c}I_{p} \mathrm{eV} \text { of } \\
\text { donor }\end{array}$ & $\begin{array}{c}E_{a} \mathrm{eV} \text { of } \\
\text { acceptor }\end{array}$ & $\begin{array}{c}C \mathrm{eV} \\
C=C^{-}+C^{+}\end{array}$ & $E_{e t} \mathrm{eV}$ \\
\hline PA cis & 6.1634 & 1.4768 & 0.79375 & 3.89285 \\
PA trans & 5.8374 & 1.4768 & 0.65737 & 3.70323 \\
PH cis & 5.8105 & 1.4768 & 0.68359 & 3.65011 \\
PH trans & 5.7106 & 1.4768 & 0.68382 & 3.54998 \\
m-PA & 6.5819 & 4.2400 & 1.23836 & 1.10354 \\
${\mathrm{PA}-\mathrm{No}_{2} \text { cis }}_{\mathrm{PA}-\mathrm{NO}_{2} \text { trans }}$ & 6.5819 & 2.9200 & 1.38930 & 2.27260 \\
$\mathrm{PA}-\mathrm{Br}$ cis & 6.5819 & 2.7630 & 1.24741 & 2.57149 \\
$\mathrm{PA}-\mathrm{Br}$ trans & 6.2668 & 1.4768 & 0.73402 & 4.29438 \\
$\mathrm{NAA}$ cis & 6.5819 & 2.1146 & 1.40921 & 3.05809 \\
NAA trans & 6.5819 & 2.2656 & 1.58205 & 2.73425 \\
ASP & 6.5819 & 1.9173 & 1.40856 & 3.25604 \\
TASP & 6.5819 & 2.3979 & 1.37789 & 2.80611 \\
\hline
\end{tabular}

N.B. Ionization potential of cytosine is $6.5819 \mathrm{eV}$ when it acts as donor. Electron affinity of cytosine is $1.4768 \mathrm{eV}$ when it acts as acceptor.

\subsection{Spectral Studies}

The UV spectra of PA have been scanned in solvents of different polarities such as ethanol, methanol, isopropanol, carbon tetrachloride and distilled water. It has been noticed that the life-time $\tau$ of the excitation has its maximum value in case of $\mathrm{CC}_{4}$ solvent, $8.93 \mathrm{~ns}$. The electronic transition energies in PA spectra have been blue shifted with increasing the solvent polarity from 261 $\mathrm{nm}$ in $\mathrm{CC}_{4}$ solvent to $243 \mathrm{~nm}$ in $\mathrm{H}_{2} \mathrm{O}$ solvent, Table 7. The Einstein transition probabilities, $A_{i f}$ and $B_{i f}$, have their maximum values in the case of isopropanol as a solvent, $7.37 \times 10^{8} \mathrm{~s}^{-1}$ and $2.28 \times 10^{9} \mathrm{sg}^{-1}$ respectively as 
Table 5. Electron transfer energies of the studied compounds with Uracil.

\begin{tabular}{|c|c|c|c|c|}
\hline Compound & $\begin{array}{c}I_{p} \mathrm{eV} \text { of } \\
\text { donor }\end{array}$ & $\begin{array}{l}E_{a} \mathrm{eV} \text { of } \\
\text { acceptor }\end{array}$ & $\begin{array}{c}C \mathrm{eV} \\
C=C^{-}+C^{+}\end{array}$ & $E_{e t} \mathrm{eV}$ \\
\hline PA cis & 6.1634 & 1.8626 & 0.19885 & 4.10195 \\
\hline PA trans & 5.8374 & 1.8626 & 0.06183 & 3.91297 \\
\hline $\mathrm{PH}$ cis & 5.8105 & 1.8626 & 0.08869 & 3.85921 \\
\hline PH trans & 5.7106 & 1.8626 & 0.17828 & 3.66972 \\
\hline $\mathrm{m}-\mathrm{PA}$ & 7.3316 & 4.2400 & 0.50251 & 2.58909 \\
\hline $\mathrm{PA}-\mathrm{No}_{2}$ cis & 7.3316 & 2.9200 & 0.65345 & 3.75815 \\
\hline $\mathrm{PA}-\mathrm{NO}_{2}$ trans & 7.3316 & 2.7630 & 0.51155 & 4.42949 \\
\hline $\mathrm{PA}-\mathrm{Br}$ cis & 6.5052 & 1.8626 & 0.13911 & 4.50349 \\
\hline PA-Br trans & 6.2668 & 1.8626 & 0.31727 & 4.08693 \\
\hline NAA cis & 7.3316 & 2.1146 & 0.67336 & 4.54364 \\
\hline NAA trans & 7.3316 & 2.2656 & 0.84582 & 4.22018 \\
\hline ASP & 7.3316 & 1.9173 & 0.67271 & 4.74159 \\
\hline TASP & 7.3316 & 2.3979 & 0.64203 & 4.29167 \\
\hline
\end{tabular}

N.B. Ionization potential of uracil is $7.3316 \mathrm{eV}$ when it acts as donor. Electron affinity of uracil is $1.8626 \mathrm{eV}$ when it acts as acceptor.

Table 6. The Cancer energy barrier, $E_{e t}$ of the studied compounds with N.A.B.

\begin{tabular}{cccccccc}
\hline \multirow{2}{*}{ N.A.B } & m-pa & naa.ci & naa.tr & Pa.Br & Pa.Br & ASP & TASP \\
& $E_{e t} \mathrm{eV}$ & $E_{e t} \mathrm{eV}$ & $E_{e t} \mathrm{eV}$ & ci. $E_{e t} \mathrm{ev}$ & tr. $E_{e t} \mathrm{ev}$ & $E_{e t} \mathrm{eV}$ & $E_{e t} \mathrm{eV}$ \\
\hline Adenine & 1.811 & 3.80 & 3.476 & 5.012 & 4.596 & 3.998 & 3.548 \\
Guanine & 0.382 & 2.341 & 2.017 & 4.417 & 4.000 & 2.539 & 2.089 \\
Cytosine & 1.104 & 3.058 & 2.734 & 4.294 & 4.056 & 4.742 & 4.292 \\
Uracil & 2.589 & 4.544 & 4.220 & 4.503 & 4.087 & 4.742 & 4.292 \\
\hline
\end{tabular}

well as the dipole strength $D_{\text {if }}$ has its maximum value in the same solvent, $1.57 \times 10^{-16}$, Table 7 .

From DFT calculations of PA molecules, Table 8, it has been found that the cis form and the transform have small energy difference, Table $1,0.16055 \mathrm{eV}$, at $27^{\circ} \mathrm{C}$. Normally the presence of conformers of a compound produces duplicity at the top of the absorption band [23] suffering from relative intensity change by the heat effect. But the electronic absorption spectrum of PA in ethyl alcohol as a solvent at $249 \mathrm{~nm}$, Figure 8 doesn't show the duplicity and the relative intensity change by the heat effect, in spite of the presence of these conformers by DFT calculations, Table 1 . The absence of the duplicity of the relative intensity change is coming from the coincidence of the same electronic transitions for the two conformers as shown in Tables 9(a) and (b) of the CIcalculations. It has been noticed that the calculated transition energies for both the cis and trans-conformers lie at $261 \mathrm{~nm}$ as it has been found in the spectrum of PA in CCl4 as a solvent, Table 7.

The complex of $\mathrm{PA}_{2}-\mathrm{Zn}$ has been prepared by ElShahawy et al. [24] since 2007. The complex had been performed bychelation of zinc ion as ethanolic solution
Table 7. The Einstein transition probabilities $\left(A_{i f} \& B_{i f}\right)$, dipole strength $\left(D_{i f}\right)$, oscillator strength $\left(f_{i f}\right)$ and life-time $\tau$ of the electronic transition bands of PA in different solvents.

\begin{tabular}{ccccccc}
\hline \multirow{2}{*}{ Solvent } & $\begin{array}{c}\lambda_{\max } \\
\mathrm{nm}\end{array}$ & $\begin{array}{c}A_{\text {if }} \times 10^{-8} \\
\mathrm{~s}^{-1}\end{array}$ & $\begin{array}{c}B_{\text {if }} \times 10^{-9} \\
\mathrm{sg}^{-1}\end{array}$ & $D_{\text {if }} \times 10^{16}$ & $f_{\text {if }}$ & $\tau$ ns \\
\hline Isopropanol & 249 & 7.3699 & 2.2787 & 1.5716 & 0.685 & 1.3569 \\
Ethanol & 249 & 4.9119 & 1.5187 & 1.0474 & 0.457 & 2.0359 \\
Methanol & 248 & 4.7479 & 1.4504 & 1.0003 & 0.438 & 2.1062 \\
$\mathrm{CCl}_{4}$ & 261 & 1.1199 & 0.3988 & 0.2750 & 0.114 & 8.9296 \\
Water & 243 & 1.9083 & 0.5484 & 0.3782 & 0.169 & 5.2403 \\
\hline
\end{tabular}

ns is nanosecond.

Table 8. DFT(B3LYP/6-31**G) parameters of the studied compounds.

\begin{tabular}{cccc}
\hline Compound & TE au & $I_{p}$ ev & $E_{a}$ ev \\
\hline PA-cis & -515.3532 & 6.1634 & 0.9162 \\
PA-trans & -515.3591 & 5.8374 & 0.6640 \\
PH-cis & $-593.95 \mathrm{au}$ & 5.8105 & 0.9265 \\
PH-trans & $-593.96 \mathrm{au}$ & 5.7106 & 0.5712 \\
M-PA & -514.08867 & 7.3112 & 4.2400 \\
PA-NO $_{2}$ cis & -644.57486 & 7.9408 & 2.9200 \\
PA-NO $_{2}$ trans & -644.58755 & 7.1588 & 2.7630 \\
PA-Br cis & -3011.1612 & 6.5052 & 1.2327 \\
PA-Br trans & -3011.1679 & 6.2668 & 1.0536 \\
NAA-cis & -628.67038 & 6.8347 & 2.1146 \\
NAA-trans & -628.64232 & 7.0309 & 2.2656 \\
ASP & -648.50274 & 7.3865 & 1.9173 \\
TASP & -971.41183 & 6.8910 & 2.3979 \\
ADENINE & -467.17488 & 6.4061 & 1.2672 \\
GUANINE & -542.37704 & 6.1879 & 1.2828 \\
CYTOSINE & -394.82291 & 6.5819 & 1.4768 \\
URACIL & -414.70313 & 7.3316 & 1.8626 \\
\hline
\end{tabular}

$\mathrm{TE}$ is the total energy in au unit. $I_{p}$ is the ionization energy in $\mathrm{eV}$ unit. $E_{a}$ is the electron affinity in $\mathrm{eV}$ unit.

of zinc acetate dihydrate with PA to form $\mathrm{PA}_{2}$ - $\mathrm{Zn}$ complex by refluxing the ethanolic solution of them. The DFT calculations were done via B3LYP/6-311*G [25], to get its ionization potential and electron affinity for the minimum energy structure of $\mathrm{PA}_{2} \mathrm{Zn}$, Figure 9.

From DFT calculations, it has been found that the chelation of $\mathrm{Zn}$ ion with cis-PA in their complex decreases the ionization potential from 6.1634 to 5.63249 $\mathrm{eV}$ and increases the electron affinity from 0.9162 to $1.39785 \mathrm{eV}$. Also, it can be noticed that the complex of PA drug is better than PA itself because there isn't amino hydrogen atom preventing the formation of the quinoide structure which has high carcinogenic effect as in the metabolized PA in the liver.

The UV spectra of ASP have been scanned in different solvents of different polarities such as ethanol, methanol, 


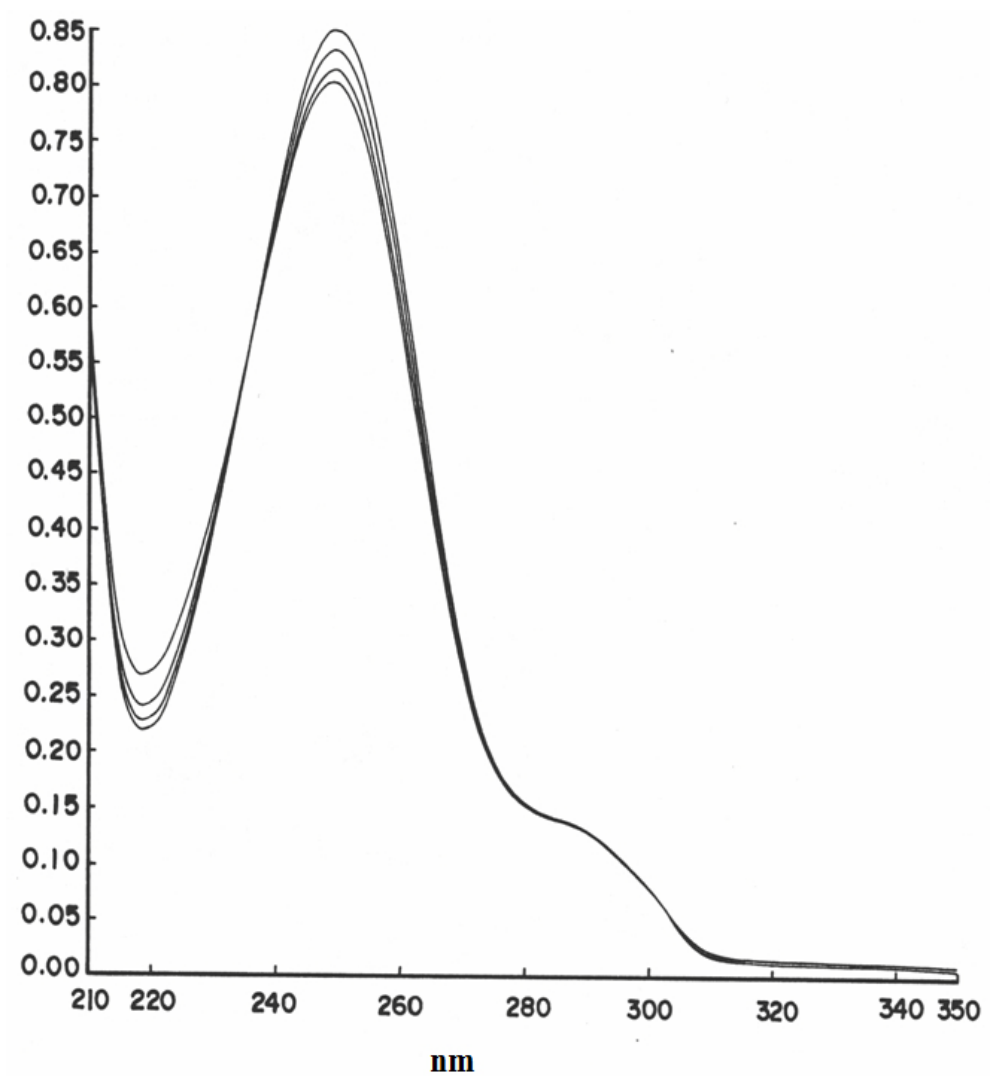

Figure 8. The heat effect on the electronic spectrum of PA molecule in EtOH. (a) at $\left(45^{\circ} \mathrm{C}\right)$, (b) at $\left(35^{\circ} \mathrm{C}\right),(\mathrm{c})$ at $\left(25^{\circ} \mathrm{C}\right)$, (d) at $\left(15^{\circ} \mathrm{C}\right)$.

Table 9. (a) Singlet Excited Transition States of cis-PA; (b) Singlet Excited Transition States of trans-PA.

(a)

\begin{tabular}{cccccc}
\hline Ex. State & Paraceta mol (cis) & $\Delta E$ ev & $\Delta E \mathrm{~nm}$ & $f$ & $\Delta E$ exp. nm \\
\hline$\Psi_{\text {exc1 }}$ & $-0.34628 \Psi_{27} \Psi_{30}+0.59941 \Psi_{27} \Psi_{32}$ & 3.7078 & 334.4 & 0.0014 & \\
$\Psi_{\text {exc2 }}$ & $-0.30680 \Psi_{28} \Psi_{30}-0.11867 \Psi_{28} \Psi_{32}$ & 4.2834 & 289.5 & 0.0546 & \\
$\Psi_{\text {exc3 }}$ & $+0.26327 \Psi_{29} \Psi_{30}+0.59007 \Psi_{29} \Psi_{31}$ & 4.6722 & 265.4 & 0.3420 & 261 \\
\hline
\end{tabular}

(b)

\begin{tabular}{cccccc}
\hline Ex. state & Paracetamol (trans) & $\Delta E$ ev & $\Delta E$ nm & $f$ & $\Delta E$ exp. nm \\
\hline$\Psi_{\text {exc1 }}$ & $0.54758 \Psi_{27} \Psi_{30}+0.4221 \Psi_{27} \Psi_{32}$ & 3.5667 & 347.6 & 0.0004 & \\
$\Psi_{\text {exc2 }}$ & $-0.26644 \Psi_{28} \Psi_{30}+0.21011 \Psi_{28} \Psi_{32}$ & & & \\
& $-0.11058 \Psi_{29} \Psi_{30}+0.60556 \Psi_{29} \Psi_{31}$ & 4.2745 & 290.1 & 0.0558 & \\
$\Psi_{\text {exc3 }}$ & $0.15788 \Psi_{28} \Psi_{31}+0.64183 \Psi_{29} \Psi_{30}+0.10783 \Psi_{29} \Psi_{31}-0.15680 \Psi_{29} \Psi_{32}$ & 4.5535 & 272.3 & 0.3250 & 261 \\
\hline
\end{tabular}

Where $\Delta E$, is the transition energy between the ground state, $\Psi_{0}$ and the excited states $\Psi_{\text {exc }}$.

isopropanol, chloroform, diethyl ether and distilled water, Figure 10. It has been noticed that the life time $\tau$ of the excitation has its maximum value in case of diethyl ether solvent, 237 ns. The electronic transition energies in ASP UV spectra have been red shifted with decreasing the solvent polarity from $275 \mathrm{~nm}$ in $\mathrm{H}_{2} \mathrm{O}$ solvent to $277 \mathrm{~nm}$ in $\mathrm{CHCl}_{3}$ solvent, Table 10. The Einstein transition probabilities, $A_{i f}$ (Spontaneous transition probability) has its maximum value in case of $\mathrm{CHCl}_{3}$ solvent $9.54 \times 10^{6}$ $\mathrm{s}^{-1}$, in contrary the induced transition probability $\left(B_{i f}\right)$ and the dipole strength $\left(D_{\text {if }}\right)$ which have the maximum values in the same solvent, $1.52 \times 10^{8} \mathrm{sg}^{-1}$ and $10.50 \times 10^{-18}$ 


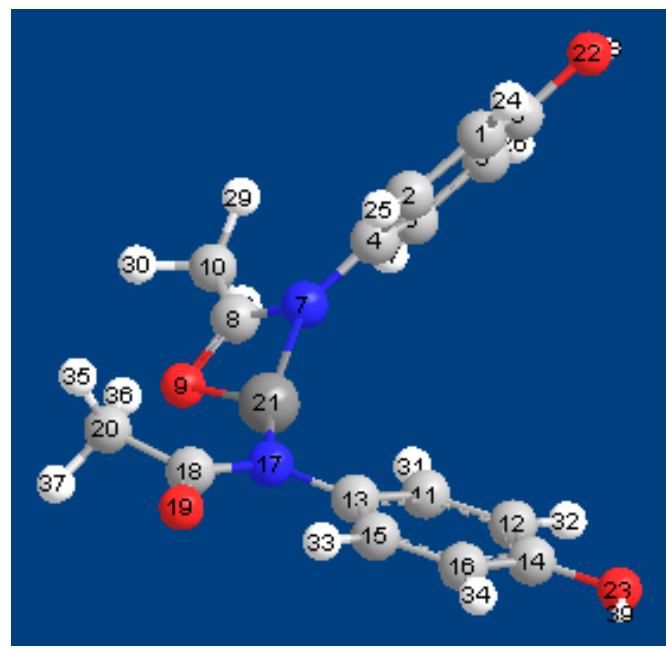

Figure 9. Minimum energy structure of $\mathbf{P A}_{2}-\mathrm{Zn}$ complex.

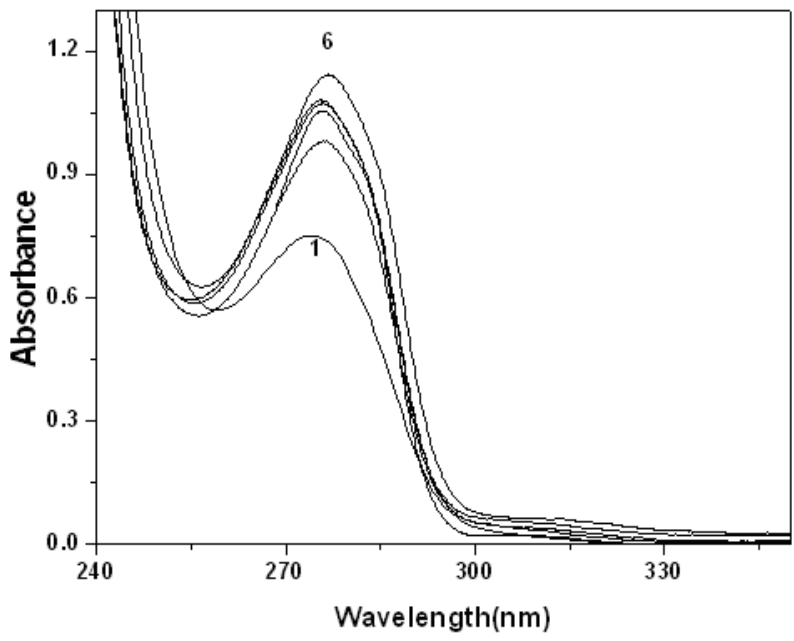

Figure 10. Electronic spectra of ASP $\left(8.6 \times 10^{-4} \mathrm{Me}^{-1}\right)$ in pure solvents $1-\mathrm{H}_{2} \mathrm{O}, 2-\mathrm{MeOH}, 3-$ Diethyl ether, 4EtOH, 5-Isopropanol and 6- $\mathrm{CHCl}_{3}$.

$\ell \mathrm{M}^{-1}$, respectively, Table 10 .

The UV spectra of TASP (thio-aspirin) have been scanned in different solvents of different polarities such as ethanol, methanol, isopropanol, chloroform, diethyl ether and distilled water, Figure 11. It has been noticed that the lifetime $\tau$ of the excitation has its maximum value in case of $\mathrm{H}_{2} \mathrm{O}$ solvent, 55.8 ns. The electronic transition energies in ATS spectra have been red shifted with decreasing the solvent polarity from $302 \mathrm{~nm}$ in $\mathrm{H}_{2} \mathrm{O}$ solvent to $313 \mathrm{~nm}$ in $\mathrm{CHCl}_{3}$ solvent, Table 11. The spontaneous Einstein transition probabilities, $A_{\text {if }}$ has its maximum value in case of diethyl ether as solvent $2.57 \times 10^{7}$ $\mathrm{s}^{-1}$ as well as the induced transition probability $\left(B_{i f}\right)$ and the dipole strength $\left(D_{i f}\right)$ which have their maximum values in the same solvent, $4.62 \times 10^{8} \mathrm{sg}^{-1}$ and $3.19 \times 10^{-17}$ $\ell \mathrm{M}^{-1}$, respectively, Table 11 .

The UV spectra of NAA have been scanned in differ- ent solvents of different polarities such as ethanol, methanol, isopropanol, chloroform, diethyl ether and dis tilled water, Figure 12. It has been noticed that the life time $\tau$ of the excitation has its maximum value in case of $\mathrm{H}_{2} \mathrm{O}$ solvent, 78.2 ns. The electronic transition energies in ATS UV spectra have been red shifted with decreasing the solvent polarity from $295 \mathrm{~nm}$ in $\mathrm{H}_{2} \mathrm{O}$ solvent to 309 $\mathrm{nm}$ in $\mathrm{CHCl}_{3}$ solvent, Table 12. The Einstein spontaneous transition probabilities, $A_{i f}$ has the maximum value in case of diethyl ether as solvent $2.11 \times 10^{7} \mathrm{~s}^{-1}$, as well as the induced transition probability $\left(B_{i f}\right)$ and the dipole strength $\left(D_{i f}\right)$ which have the maximum values in the same solvent, $3.77 \times 10^{8} \mathrm{sg}^{-1}$ and $2.60 \times 10^{-17} \mathrm{\ell M}^{-1}$, respectively, Table 12.

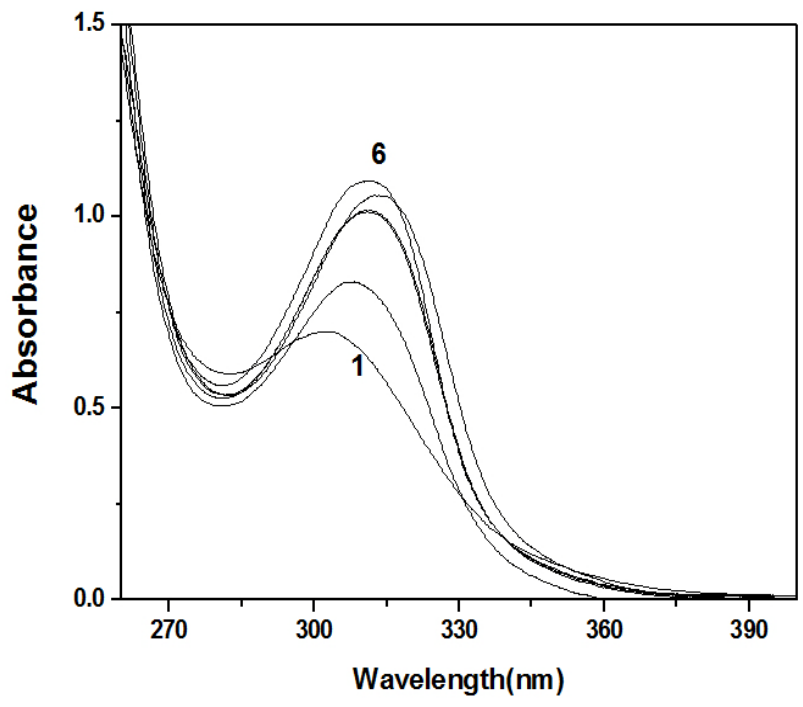

Figure 11. Electronic spectra of TASP $\left(2.25 \times 10^{-4} \mathrm{Ml}^{-1}\right)$ in pure solvents 1- $\mathrm{H}_{2} \mathrm{O}, 2-\mathrm{MeOH}, 3-\mathrm{EtOH}, 4-I s o p r o p$, $5-\mathrm{CHCl}_{3}$ and 6 - Dieth-yl ether.

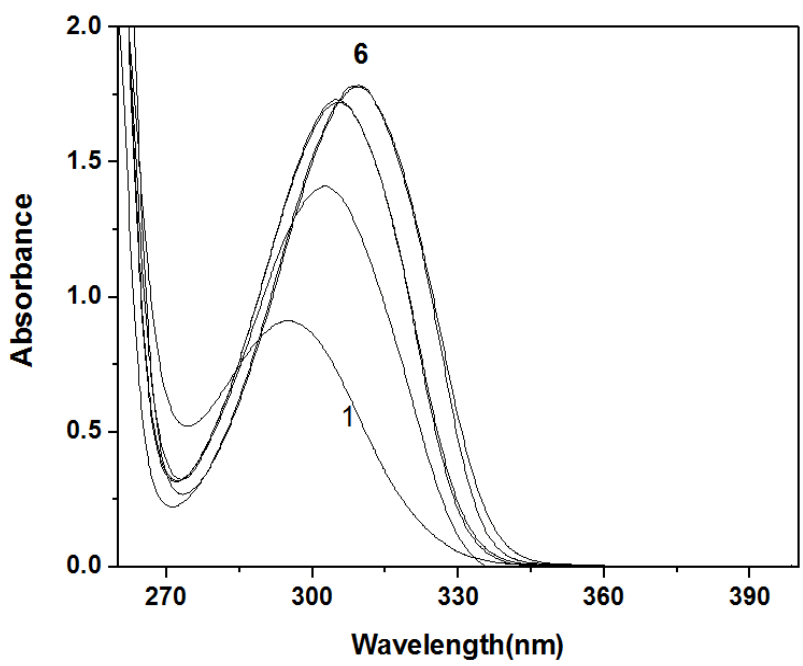

Figure 12. Electronic spectra of NAA $\left(3.5 \times 10^{-4} \mathrm{Me}^{-1}\right)$ in pure solvents 1- $\mathrm{H}_{2} \mathrm{O}, 2-\mathrm{MeOH}, 3-\mathrm{EtOH}, 4-$ Isoprop, $5-\mathrm{CHCl}_{3}$ and $6-$ Deth-yl ether. 
Table 10. The Einstein transition probabilities $\left(A_{i f}, B_{i f}\right)$, dipole moment $\left(D_{i f}\right)$, oscillator strength $\left(f_{i f}\right)$, life time $(\tau)$ and extinction coefficient $(\varepsilon)$ of the electronic transition bands of ASP in different solvents.

\begin{tabular}{ccccccccc}
\hline Solvent & $\lambda_{\max } \mathrm{nm}$ & $\mathrm{A}_{\max }$ & $\varepsilon_{\max } \times 10^{-4} \mathrm{LM}^{-1} \mathrm{~cm}^{-1}$ & $A_{\text {if }} \times 10^{-6} \mathrm{~S}^{-1}$ & $B_{\text {if }} \times 10^{-8} \mathrm{Sg}^{-1}$ & $f_{\text {if }} \mathrm{LM}^{-1} \mathrm{~cm}^{-1}$ & $\mathrm{D}_{\text {if }} \times 10^{18} \mathrm{LM}^{-1}$ & $\tau \mathrm{ns}$ \\
\hline $\mathrm{H}_{2} \mathrm{O}$ & 275 & 0.751 & 0.8732 & 4.28 & 0.678 & 0.01850 & 4.68 & 234 \\
$\mathrm{MeOH}$ & 276 & 0.98 & 1.1395 & 4.78 & 0.761 & 0.0207 & 5.25 & 209 \\
Isopropyl & 275 & 1.08 & 1.2558 & 5.30 & 0.842 & 0.0229 & 5.81 & 189 \\
$\mathrm{EtOH}$ & 276 & 1.072 & 1.2465 & 5.65 & 0.900 & 0.0244 & 6.21 & 177 \\
$\mathrm{CHCl}_{3}$ & 277 & 1.142 & 1.3279 & 9.54 & 1.52 & 0.0412 & 10.50 & 105 \\
Diethyl ether & 276 & 1.054 & 1.2255 & 4.22 & 0.671 & 0.0182 & 4.63 & 237 \\
\hline
\end{tabular}

Table 11. The Einstein transition probabilities $\left(A_{i f}, B_{i f}\right)$, dipole moment $\left(D_{i f}\right)$, oscillator strength $\left(f_{i f}\right)$, life time $(\tau)$ and extinction coefficient $(\varepsilon)$ of the electronic transition bands of TASP in different solvents.

\begin{tabular}{ccccccccc}
\hline Solvent & $\lambda_{\max } \mathrm{nm}$ & $\mathrm{A}_{\max }$ & $\varepsilon_{\max } \times 10^{-4} \mathrm{M}^{-1} \mathrm{~cm}^{-1}$ & $A_{\text {if }} \times 10^{-7} \mathrm{~S}^{-1}$ & $B_{\text {if }} \times 10^{-8} \mathrm{Sg}^{-1}$ & $f_{\text {if }} \mathrm{LM}^{-1} \mathrm{~cm}^{-1}$ & $\mathrm{D}_{\text {if }} \times 10^{17} \mathrm{LM}^{-1}$ & $\tau \mathrm{ns}$ \\
\hline $\mathrm{H}_{2} \mathrm{O}$ & 302 & 0.700 & 0.3111 & 1.79 & 3.12 & 0.0077 & 2.15 & 55.8 \\
$\mathrm{MeOH}$ & 308 & 0.830 & 0.3688 & 1.98 & 3.52 & 0.0085 & 2.43 & 50.5 \\
Isopropyl & 310 & 1.016 & 0.4515 & 2.39 & 4.28 & 0.0103 & 2.95 & 41.9 \\
$\mathrm{EtOH}$ & 311 & 1.012 & 0.4497 & 2.52 & 4.52 & 0.0109 & 3.11 & 39.8 \\
$\mathrm{CHCl}_{3}$ & 313 & 1.056 & 0.4693 & 2.56 & 4.61 & 0.0110 & 3.18 & 39.1 \\
Diethyl ether & 312 & 1.094 & 0.4862 & 2.57 & 4.62 & 0.0111 & 3.19 & 38.9 \\
\hline
\end{tabular}

Table 12. The Einstein transition probabilities $\left(A_{i f}, B_{i f}\right)$, dipole moment $\left(D_{i f}\right)$, oscillator strength $\left(f_{i f}\right)$, life time $(\tau)$ and extinction coefficient $(\varepsilon)$ of the electronic transition bands of NAA in different solvents.

\begin{tabular}{|c|c|c|c|c|c|c|c|c|}
\hline Solvent & $\lambda_{\max } \mathrm{nm}$ & $\mathrm{A}_{\max }$ & $\varepsilon_{\max } \times 10^{-4} \mathrm{LM}^{-1} \mathrm{~cm}^{-1}$ & $A_{i f} \times 10^{-7} \mathrm{~S}^{-1}$ & $B_{i f} \times 10^{-8} \mathrm{Sg}^{-1}$ & $f_{\text {if }} \mathrm{LM}^{-1} \mathrm{~cm}^{-1}$ & $\begin{array}{c}\mathrm{D}_{\text {if }} \times 10^{17} \\
\mathrm{LM}^{-1}\end{array}$ & $\tau \mathrm{ns}$ \\
\hline $\mathrm{H}_{2} \mathrm{O}$ & 295 & 0.913 & 0.2608 & 1.28 & 2.18 & 0.0552 & 1.50 & 78.2 \\
\hline $\mathrm{MeOH}$ & 302 & 1.412 & 0.4034 & 1.65 & 2.87 & 0.0711 & 1.98 & 60 \\
\hline Isoprpyl & 305 & 1.734 & 0.4954 & 1.97 & 3.46 & 0.0851 & 2.39 & 50.8 \\
\hline EtOH & 305 & 1.723 & 0.4922 & 1.99 & 3.51 & 0.0860 & 2.42 & 50.3 \\
\hline Diethyl ether & 309 & 1.785 & 0.5100 & 2.11 & 3.77 & 0.0912 & 2.60 & 47.4 \\
\hline
\end{tabular}

\section{Conclusions}

1) Paracetamol complexes are safer than PA itself.

2) It is advisable to use PA-Br as a drug instead of PA.

3) NAA compound can be used as an alternative drug instead of PA and ASP.

\section{REFERENCES}

[1] B. J. de Paramo, S. Q. Gancedo, M. Cuevas, I. P. Camo, J. A. Martin and E. L. Cosmes, "Paracetamol (Acetaminophen) Hypersensitivity,” Annals of Allergy, Asthma \& Immunology, Vol. 85, No. 6, 2000, pp. 508-511. http://dx.doi.org/10.1016/S1081-1206(10)62580-X

[2] T. Vial, A. Bergeret, D. Delattre and J. Descotes, "Side Effect of Paracetamol," Lyon Pharm, Vol. 39, No. 3, 1988, pp. 187-189.

[3] J. Wojcicki, B. Zdzislaw, G. S. Barbara, K. Joszef and K. K. Pol, "The of Single Dose of Ethanol on Pharmacokinetics of Paracetamol," Journal of Pharmacy and Phar- macology, Vol. 30, No. 6, 1978, pp. 749-753.

[4] Y. Goto, T. Niiya, N. Honjo, T. Sakamoto, H. Yoshizawa, H. Yamanaka and T. Kubot, "Molecular Orbital Study of the Reactivity of Active Alkyl Groups of Pyridine and Pyrimidine Derivatives," Chemical \& Pharmaceutical Bulletin, Vol. 30, No. 4, 1982, pp. 1126-1133. http://dx.doi.org/10.1248/cpb.30.1126

[5] H. M. Taha, F. A. Al-Obeidi and H. N. Borazan, "UV Studies of Nucleic Acid Base Complexation with Isoproterenol in Different Solvents," Journal of Pharmaceutical Sciences, Vol. 68, No. 5, 1979, p. 631. http://dx.doi.org/10.1002/jps.2600680532

[6] M. Th. Makhlouf, A. S. El-Shahawy and S. A. El-Shatory, "CNDO Study of the Tautomeric Structure of Uracil and Its Effect on the Electrochemical Corrosion Behavior of Mild Steel in Acid Media," Materials Chemistry and Physics, Vol. 43, No. 2, 1996, p. 153. http://dx.doi.org/10.1016/0254-0584(95)01611-W

[7] T. Ghafourian and J. C. Dearden, "The Use of Atomic Charges and Orbital Energies as Hydrogen-Bonding- 
Donor Parameters for QSAR Studies Comparison of MNDO. AM1, PM3 Methods,” Journal of Pharmacy and Pharmacology, Vol. 52, No. 6, 2000, pp. 603-610. http://dx.doi.org/10.1211/0022357001774435

[8] A. C. Moffat, "Clarks Isolation and Identification of Drugs,” 2nd Edition, The Pharmaceutical Press, London, 1986.

[9] F. A. Al-Obeidi and H. N. Borazan, "Interaction of Nucleic Acid Bases with Catechol: UV Studies,” Journal of Pharmaceutical Sciences, Vol. 65, No. 6, 1976, p. 892. http://dx.doi.org/10.1002/jps.2600650622

[10] J. Lahiri and R. Basu, "Estimation of Electron Affinities of Tetracycline and Oxytetracycline," Indian Journal of Chemistry, Vol. 21B, No. 3, 1982, p. 260.

[11] A. S. El-Shahawy and A. S. Hammam, "CNDO/SCF Molecular Orbital Structural Studies and Charge Transfer Complex Formation between 4,4'-Dimethoxydiquinone and Uracil," Bulletin of the Chemical Society of Ethiopia, Vol. 18, No. 2, 2004, pp. 193-204.

[12] K. Eran and K. Gideon, "Management of Paracetamol Overdose: Current Controversies,” Drug Safety, Vol. 24, No. 7, 2001, p. 503. http://dx.doi.org/10.2165/00002018-200124070-00003

[13] J. R. Vane and R. M. Botting, "The Mechanism of Action of Aspirin," Thrombosis Research, Vol. 110, No. 5-6, 2003, pp. 255-258. http://dx.doi.org/10.1016/S0049-3848(03)00379-7

[14] A. D. Becke, "Density-Functional Thermochemistry. III. The Role of Exact Exchange,” Journal of Chemical Physics, Vol. 98, 1993, p. 5648.

[15] B. A. Miehlich, H. S. Savin and H. Preuss, "Results Obtained with the Correlation Energy Density Functionals of Becke and Lee, Yang and Parr,” Chemical Physics Letters, Vol. 157, No. 3, 1989, pp. 200-206. http://dx.doi.org/10.1016/0009-2614(89)87234-3

[16] P. Hohenberg and W. Kohn, "Inhomogeneous Electron
Gas,” Physical Review, Vol. 136, No. 3B, 1964, pp. B864-B871. http://dx.doi.org/10.1103/PhysRev.136.B864

[17] W. Kohn and L. Sham, "Self-Consistent Equations Including Exchange and Correlation Effects," Physical Review, Vol. 140, No. 4A, 1965, pp. A1133-A1138. http://dx.doi.org/10.1103/PhysRev.140.A1133

[18] A. S. El-Shahawy, S. M. Ahmed and N. Kh. Sayed, "Charge Transfer Studies between Paracetamol and Nucleic Acid Bases," International Journal of Pure and Applied Chemistry, Vol. 1, No. 4, 2006, pp. 577-587.

[19] A. El-Shahawy, "Computational DFT/CI Spectroscopic Structural Studies of Some Complexes of Benzalbarbituric Acid,” Journal of Molecular Structure, Vol. 987, No. 1-3, 2011, pp. 232-240. http://dx.doi.org/10.1016/j.molstruc.2010.12.030

[20] R. F. Borne, "Nonsteroidal Anti-Inflammatory Agents," In: Williams, D.A. and Lemke, T.L., Foye's Principles of Medicinal Chemistry, 6th Edition, Lippincott Williams \& Wilkins, Philadelphia, 2007, pp. 751-793.

[21] L. F. Prescott, "Paracetamol (Acetaminophen): A Critical Bibliographic Review,” CRC Press, 1996.

[22] Wikipedia Free Encyclopedia (Paracetamol_metabolism. svg).

[23] A. S. El-Shahawy, M. M. Girgis and M. T. Ismail, "Nicotinic Acid and Nicotinamide Electronic Structural Studies," Specrochimica Acta, Vol. 43A, No. 11, 1987, pp. 1371-1375.

[24] A. S. El-Shahawy, S. M. Ahmed and N. Kh. Sayed, "INDO/SCF-CI Calculations and Structural Spectroscopic Studies of Some Complexes of 4-Hydroxyacetanilide," Spectrochimica Acta Part A: Molecular and Biomolecular Spectroscopy, Vol. 66, No. 1, 2007, pp. 143-152. http://dx.doi.org/10.1016/j.saa.2006.02.034

[25] A. El-Shahawy, "Bases of Quantum Chemistry,” Lambert, 2013. 